\title{
Statistical Methods in Building Industry to Determine Prices Indices
}

\author{
Helena Ellingerová, Zora Petráková, Ingrida Skalíková*
}

\begin{abstract}
Tender price is often affected by the location of the construction, which is usually determined by the investor, and it has an impact on the traffic in the particular location Individual time of supply and the method of realization play an important role as well. They both are determined by the investor along with the designer of the particular construction. Contractors often complain about the lack of time needed for the preparation of their tender prices. Therefore, it is necessary to look for the possibilities how to reliably speed up this process at the same time taking into account all of the specific features of a structure. This article deals with the application of two statistical methods. The Pareto analysis, which can be used during the design of the tender price, and the extrapolation method, which can be used for the estimation of the price development, based on the regression analysis of the time series. The results of the article particularly serve to contractors in the building industry to better prepare their price offers in tenders. The findings of this document may also be applicable in other countries which have a similar economic profile as Slovakia.
\end{abstract}

Keywords: building industry; Pareto analysis; prices indices; statistical methods

\section{INTRODUCTION}

Based on the needs of the construction practice, certain statistical methods are used more frequently. Their aim is to analyze several problems within the investment process during the preparation and the realization phase of the construction contract. For the contractor, the design of the tender price is one of the most difficult problems.

This price represents the price for which he is willing to perform the contract. The tender price must take into account all the specifics of the construction contract, which result from the individuality and the character of the particular construction, such as the layout, the design, the architectural solution, as well as the operational and ecological solutions of a structure [14].

The main role of a statistical method is typically to examine the mass phenomena and the variability of their expression. The essential element is the design of a database by collecting all the necessary information, define the set of statistical parameters, and finally to analyze all the examined phenomena. Methods of statistical analysis provide a particular set of techniques for quantification of the basic statistical set of regularities or the sample of files for the purpose of their use in the subsequent practical activities [4]. The issue of offers in the construction sector is the subject of interest of several scientific publications, not only in the Slovak Republic but also in other Central European countries such as Poland, Czech Republic and Hungary [13, 5].

Current trend in building industry is to reduce the workload in preparing the offering price of the commission. Traditional methods of determining the offering price using the detailed budget are being replaced by innovative approaches for evaluating the building flow already in the phase of construction preparation. One of these innovative approaches of determining the offering price is a form of parametric budgeting. This method using parametric estimate of expenses and other related mathematical statistical methods (regression function CER - Cost Estimating Relationships) is already showing results in Czech Republic [22].
Time factor is often being omitted in preparation of a bid, primarily for reasons of competitiveness, which is not always the correct procedure because some time always passes between the preparation of the bid and the final realization. The prices of building work and materials as well as other commodities change their value over time; therefore, it is sensible to account for this development, especially during times of greater value deviation, by adjusting the offering price by a reasonable amount. This article explores this problem and its solution using the second degree multinomial.

\subsection{Literature Research}

Ernest, Theophilus, Amoah \& Emmanuel [6] conducted a quantitative survey in the form of a questionnaire containing 23 economic indicators. The results of the study point to the most important economic indicators to be taken into account in creating the offer in construction tenders. Those are as follows: the gross domestic product of the country (GDP), interest rates, exchange rate (exchange rate risk), and consumer price index.

Samani, Gregory, Leal, Mendes, \& Correia [18] in their analysis point out, that LCCA (Life Cycle Cost Analysis) is a tool for assessing the costs associated with building life cycle phases in the building industry. The life-cycle phases of a building are the following: preparation, implementation, operation and change of the purpose of use, eventually liquidation.

The authors, in the conclusions of their study in American cities, believe that the location of the building with the impact of the rate of maintenance cost inflation (rising energy and safety costs) is also a factor that is not negligible in creating price offers in tenders. Amuda Yusuf \& Mohamed [2] dealt with cost management and economy-effectiveness of the costs of the entire life cycle of the building. The authors came to the conclusion based on structured interviews and questionnaire surveys: adopting a pricing mechanism based on standards (of the most advanced countries in the world) could increase the quality of prediction of tender's price 
offers in construction in all stages of the life cycle of a building. They also point to the use of mathematicalstatistical methods in their creation.

The authors [17], point to the importance of statistical methods in pricing in tenders in the building sector, focusing in particular on the life cycle of the building. The authors point to the use of the Pareto optimum method and its boundary. The article highlights not only the benefits of using Pareto's optimum but also the shortcomings. In conclusion, the authors highlight the need for consultation and expert discussion using any statistical method used to predict an offer in the construction sector.

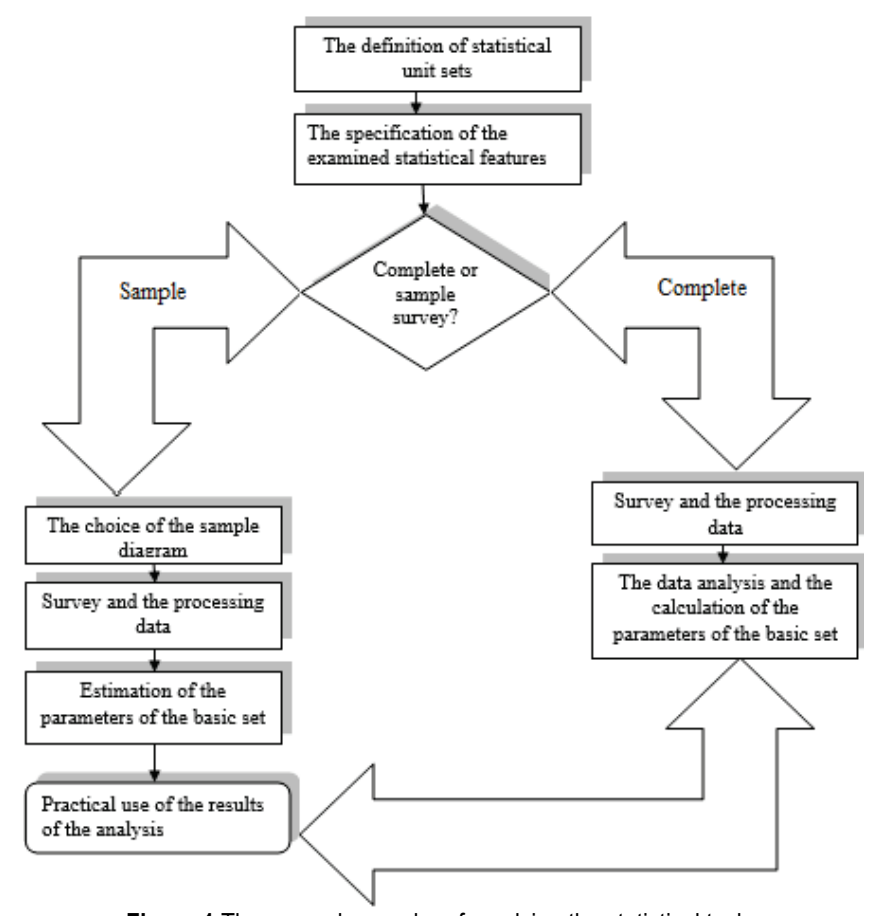

Figure 1 The general procedure for solving the statistical tasks.

In the construction practice, those statistical methods may also have a practical use, especially during the design of the tender price from the contractor's point of view, in his company's pricing policy [11].

\subsection{The Specific of the Researched Phenomena within the Price Policy of the Contractor}

The pricing policy is considered to be developed as the weakest, but it is also an applied tool for the marketing mix in the construction industry. Nevertheless, the price is an important factor of every construction company's success in the business [19].

Instead of the individual price policy, which responds to a specific part of a construction production, for the preparation of the construction contract Slovak construction companies still use the tender prices, which only indicate the approximate prices of all the construction works. These are annually published by several companies, which deal with the price settings within the construction industry. The explanation for this can be the fact that the Slovak market is still not a well-functioning competitive market. At first it may seem that the construction companies which are fighting for contracts must be involved in a competitive battle, uncompromisingly forcing into the individual calculation of the tender price [16]. However, the commonly irresponsible approach of many public works authorities as well as many smaller developers to an agreement on the construction's price is negated by the amount of competition.

The construction production commitment to the location of a structure partially lowers down the competition pressure of the companies from farther locations. This is noticeable when they try to compete with the individual construction works. This kind of market does not motivate the construction companies to watch their own actual costs and neither to the creation of their own pricing database, which could take into account the specific needs of each and every construction company, and not only in the cost, but also in the profitable area.

This situation illustrates the common reaction of the construction companies to the question why they do not own their own pricing database. They claim that they do not need one, since those indicative approximate prices include sufficiently high percentage charges of the overheads and profits, which cover their cost, and they provide the necessary prosperity as well.

However, this situation changes due to the entry of foreign investors, as well as foreign construction companies. The foreign investors are used to the professionally performed offer control and to the supply activities of companies and their invoices. The foreign construction competition enters the distant markets only with their own management and technical capacity, hiring domestic subcontractors for the majority of the construction works whereupon they will have to comply with the conditions of the general contractors.

Therefore, the problematic dealing with the pricing policy of construction companies is extremely current. It requires the application of all available comprehensive approaches within the pricing itself, using all the existing mathematical-statistical methods in order to design the tender price which will be competitive for the contractor but also acceptable for the investor.

\subsubsection{Pareto Analysis}

During the design phase of the tender, every construction company should put into effect mainly their own, individually calculated prices. The individuality of the calculation does not mean that a fully new calculation of the price for every contract has to be made. However, this would definitely be the most precise way in terms of labor intensity, it would be unrealistic to manage this enormous number of items that would need to be calculated in certain time limit (of putting out the offer). Therefore, the company's own pricing database of construction works needs to be regularly updated. The other option would be to look for a way to speed up the designing process of the tender price by creating the tender budget. The Pareto analysis presents this kind of possibility [23]. 
The Pareto analysis is based upon the assumption that we own a database of statistical units which is divided in the ratio of $80 / 20$, according to the particular criteria by the Pareto rule (upon the cost level, when dealing with the design of the tender price).

First, upon the specified report and assessment of the contracting authority, the contractor will design a cost budget using only approximate prices. As a next step, the final price of a structure will be adjusted from the approximate valuation, and it will be recalculated according to the individual conditions by adjusting part of the budget items into individual prices. For this purpose, the Pareto analysis will be applied. Items form the report and assessments, which represent $80 \%$ of the total price of a structure, will be taken out. According to the rule mentioned earlier, this should represent approximately $20 \%$ of all the items of the report and assessment. The remaining $80 \%$ of the total amount of items (with the share price of 20\%) stays unchanged, without any changes of the unit price [21].

According to [24], the procedure steps of the Pareto analysis are the following: 1) The set of statistical units must be specified by the report and assessment items (it consists of numerous measurement units of works); 2) The amount of measurement units has to be priced by the approximate unit prices; 3) All the individual items according to the total price must be sorted in a descending order; 4) Corresponding cumulated sums of prices have to be calculated according to the order and the $80 \%$ border line of the total approximate price must be determined; 5) The limit of the amount of the items must be determined from the total amount of items which will be analyzed primarily (they will be individually calculated by company's rates); 6) Specific items and their unit prices have to be recalculated by the company's overhead and profit rates [3].

Thanks to this procedure, the numerical data dealing with the share of individual items on the total offer price will be available. Currently, there are several pricing programs in Slovakia, which allow the users to simulate the development of costs in the individual calculation within the price making process of a company.

For the contractor, the Pareto analysis output represents the information about the kinds of items and their serial numbers within the budget that can be considered bearing, and whose overall costs represent $80 \%$ of the total tender price of the contract. Another output of the Pareto analysis is the information about the percentage of the mentioned bearing items, which are present within the total amount of priced items in the budget.

However, the comprehensive comparison based on the analysis of total prices, profit, and individual cost items, which enter the price (such as material, salaries, machines, overheads, etc.), provides better information specified in the following levels:

- the calculation based on the indicative unit prices,

- the calculation based on the individually of calculated bearing items according to the company's overhead rates and the required profit of the contractor,

- the calculation based on the individually of calculated bearing items according to the company`s overhead rates and the required profit of the contractor including the possibility of discount on specific type of material.

The recalculation of bearing items by the company's overhead rates and profits will create a difference between the total price of the budget with the approximate prices and the individually calculated tender price of the contractor. This means that the contractor has applied the strategy of company's prices within the bearing items (individual calculation of unit prices according to the company's rates from the inner bookkeeping). This way, the contractor will be able to offer works along with the price taking into consideration the needs of the company; maybe even with lower prices than the presented offer, only based on the approximate prices, i.e., pricing the report and assessment by approximate unit prices of the existing database. Contractor's application of the Pareto analysis in practice, using the "bearing items" function of the existing pricing software, provides the creation of the tender price with less work involved. In case the company is provided with the wellprepared inner bookkeeping, the price offer should be even more accurate in regard to the planned economical effectiveness of the contract (ratability of costs, sales and profits).

\subsection{The Method of the Price Development Forecast Based on the Analysis of the Time Series with the Seasonal Component}

During the design of the tender price, due to the competitiveness, the time factor is often neglected. However, this is not the right approach, because there is always some time passed from the beginning of the design of the tender price until the end of the realization of a contract. The prices of construction work and materials, as well as other commodities, change their values in time. This trend is followed up by the Statistical Office of the Slovak Republic, which processes the index of development of prices. They are published monthly and quarterly on their website.

During the design of the tender, it is very smart to take into consideration the development of prices, especially during the price fluctuations. Therefore, this risk of price change shall be calculated into the offer price using a reasonably acceptable amount [8]; especially, if the developer constructor (investor) insists on the agreement on the tender price without any possibility of its adjustment (fixed price) [10].

The expected trend in the construction price development for the period of the next three years or for the estimated time of the construction can be created using individual features of MS Excel program. In our study mentioned below, with the time horizon since 2020, we have used this trend estimation, using the exact methods of prediction, such as the extrapolation method, which is based on the regression analysis of the time series with the seasonal component.

In the forecast of the development of prices, the price index of the construction works, materials and products used within the construction, will be representing the input data 
during the time of the realization of a contract, and they will be quarterly published by the Statistical Office of the Slovak Republic. The overview of the past price development can be gained based on the mentioned statistical indices. They form the ultimate information for their next forecasts.

If no significant changes are anticipated within the price levels of the construction and mounting works, the appropriate method to use would be the method of extrapolation of trends. The purpose of this method is to analyze the time series of the examined statistical indices; to determine the trend line and to extend the trends into the future. By extending the trend, the estimated value of the index in the future quarters can be achieved.

The feature of the trend must be registered by a formalized relationship, i.e. by a particular mathematical formula, so that the calculation of predicted values is ensured [9]. In order to find a particular trend line, it is necessary to know their individual types and regression equations. The trend lines, which are used the most during the design of the extrapolation forecasts (prognosis), contain two or three parameters. Based on the significance of the estimation of the parameters of the trend line, a second-degree polynomial has been chosen [11].

\subsection{Results}

The time series of quarterly indices of prices in the construction industry since the first quarter of 2003 until the fourth quarter of 2019 for single-apartment buildings (family house type of buildings- according to ŠKS 1110 section of
JKSO 803 - residential buildings) will be analyzed and compared to the already known fact (first and fourth quarter of 2019), in the presented example (case study).

Table 1 The time series of the indices for buildings KS no. 111 (section no. 803 Residential buildings).

\begin{tabular}{|c|c|c|c|c|c|c|}
\hline & 1 & 2 & 3 & 4 & 5 & 6 \\
\hline \multirow{2}{*}{ I } & \multirow{2}{*}{ Year } & \multicolumn{4}{|c|}{ QUARTER } & \multirow{2}{*}{ Sum } \\
\hline & & I. & II. & III. & IV. & \\
\hline 1 & 2003 & 1,013 & 1,010 & 1,013 & 1,009 & 4,04500 \\
\hline 2 & 2004 & 1,025 & 1,019 & 1,021 & 1,009 & 4,07400 \\
\hline 3 & 2005 & 1,013 & 1,008 & 1,009 & 1,008 & 4,03800 \\
\hline 4 & 2006 & 1,013 & 1,010 & 1,009 & 1,009 & 4,04100 \\
\hline 5 & 2007 & 1,017 & 1,009 & 1,011 & 1,011 & 4,04800 \\
\hline 6 & 2008 & 1,021 & 1,018 & 1,013 & 1,007 & 4,05900 \\
\hline 7 & 2009 & 1,008 & 1,009 & 0,995 & 1,000 & 4,01200 \\
\hline 8 & 2010 & 1,000 & 0,997 & 1,002 & 1,001 & 4,00000 \\
\hline 9 & 2011 & 1,003 & 1,001 & 1,003 & 1,000 & 4,00700 \\
\hline 10 & 2012 & 0,998 & 1,003 & 1,002 & 0,998 & 4,00100 \\
\hline 11 & 2013 & 0,999 & 1,001 & 1,005 & 1,005 & 4,01000 \\
\hline 12 & 2014 & 1,002 & 1,003 & 1,003 & 1,001 & 4,00900 \\
\hline 13 & 2015 & 1,006 & 1,004 & 1,006 & 1,003 & 4,01900 \\
\hline 14 & 2016 & 1,001 & 1,004 & 1,004 & 0,999 & 4,00800 \\
\hline 15 & 2017 & 1,014 & 1,016 & 1,004 & 1,003 & 4,03700 \\
\hline 16 & 2018 & 1,013 & 1,008 & 1,008 & 1,007 & 4,03600 \\
\hline 17 & 2019 & 1,017 & 1,007 & 1,009 & 1,004 & 4,03700 \\
\hline \multicolumn{2}{|c|}{ Sum } & 17,163 & 17,127 & 17,117 & 17,074 & 68,481 \\
\hline
\end{tabular}

*In Tab. 1 the term $i=1,2,3, \ldots, 9$, where $i=1$ corresponds to 2003 .

Using the MS Excel program, it is possible to create the trend line and its formula (regression equation), which helps to determine the estimated development of index prices for the next period.

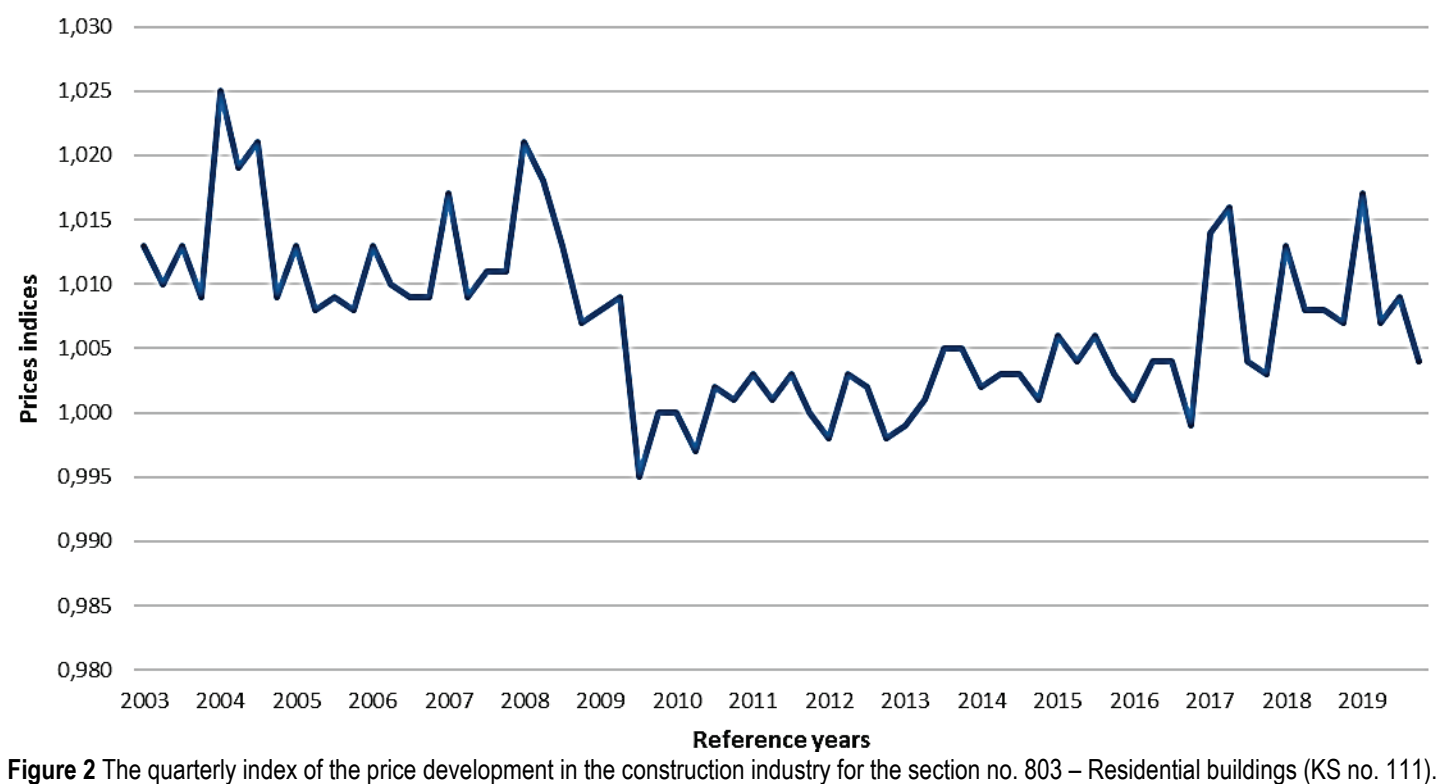

In the example mentioned above (Fig. 3), the trend line represents the second-degree polynomial. The formula of the trend line is following:

$y(x)=0.00001 x^{2}-0.0008 x+1.019$ where $x$ represents the particular time term to determine the value of the index $y(x)$.

The following Tab. 2 represents the forecast of the development of price indices for the next three years (the substitution of $x$ in the equation of the trend line, for the value beginning with the value of 69 , since the trend line, which is drawn according to the time series contains 68 input data). 
The trend function of the $2^{\text {nd }}$ degree polynomial

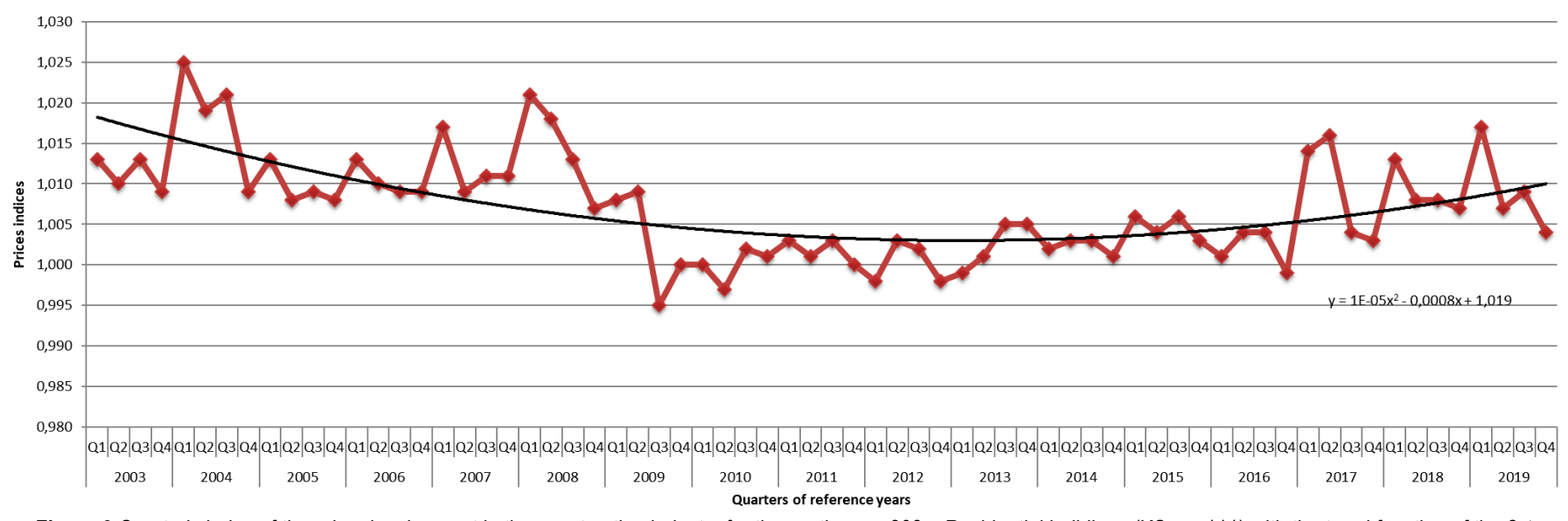

Figure 3 Quarterly index of the price development in the construction industry for the section no. 803 - Residential buildings (KS no. 111) with the trend function of the $2^{\text {nd }}$ degree polynomial.

Table 2 The values of the quarterly indices for the section no. 803 - Residential buildings (KS no. 1110) for the next three years, using the trend without the seasonal component.

\begin{tabular}{|l|c|c|c|}
\hline & \multicolumn{3}{|c|}{ Year } \\
\hline \multicolumn{1}{|c|}{ Quarter } & 2020 & 2021 & 2022 \\
\hline $1^{\text {st }}$ quarter & 1,00962 & 1,00919 & 1,00878 \\
\hline $2^{\text {nd }}$ quarter & 1,00812 & 1,00769 & 1,00728 \\
\hline $3^{\text {rd }}$ quarter & 1,00798 & 1,00755 & 1,00714 \\
\hline $4^{\text {th }}$ quarter & 1,00976 & 1,00933 & 1,00892 \\
\hline
\end{tabular}

This example only represents the general procedure of the trend setting. However, it is not recommended to use it in this form. It is necessary to make an analysis of the seasonal component, because the trend does not say anything about the seasonality.

In case of time series with a seasonal component, it is necessary to individually analyze the trend section, as well as to individually analyze the seasonal section of time series. It has to be done, because in terms of the repeating seasonality the time series has a developing trend [12].

Table 3 Time series of price indices for residential buildings with the seasonal component.

\begin{tabular}{|c|c|c|c|c|c|c|c|c|c|}
\hline \multirow{3}{*}{1} & \multirow{3}{*}{$i$} & 1 & 2 & 3 & 4 & 5 & 6 & 7 & 8 \\
\hline & & \multirow{2}{*}{ Year } & \multicolumn{4}{|c|}{ QUARTER } & \multirow{2}{*}{ Sum } & \multirow[b]{2}{*}{$y_{i}$} & \multirow{2}{*}{$i \cdot y_{i}$} \\
\hline & & & I. & II. & III. & IV. & & & \\
\hline 2 & 1 & 2003 & 1,013 & 1,010 & 1,013 & 1,009 & 4,04500 & 1,01125 & 1,01125 \\
\hline 3 & 2 & 2004 & 1,025 & 1,019 & 1,021 & 1,009 & 4,07400 & 1,01850 & 2,03700 \\
\hline 4 & 3 & 2005 & 1,013 & 1,008 & 1,009 & 1,008 & 4,03800 & 1,00950 & 3,02850 \\
\hline 5 & 4 & 2006 & 1,013 & 1,010 & 1,009 & 1,009 & 4,04100 & 1,01025 & 4,04100 \\
\hline 6 & 5 & 2007 & 1,017 & 1,009 & 1,011 & 1,011 & 4,04800 & 1,01200 & 5,06000 \\
\hline 7 & 6 & 2008 & 1,021 & 1,018 & 1,013 & 1,007 & 4,05900 & 1,01475 & 6,08850 \\
\hline 8 & 7 & 2009 & 1,008 & 1,009 & 0,995 & 1,000 & 4,01200 & 1,00300 & 7,02100 \\
\hline 9 & 8 & 2010 & 1,000 & 0,997 & 1,002 & 1,001 & 4,00000 & 1,00000 & 8,00000 \\
\hline 10 & 9 & 2011 & 1,003 & 1,001 & 1,003 & 1,000 & 4,00700 & 1,00175 & 9,01575 \\
\hline 11 & 10 & 2012 & 0,998 & 1,003 & 1,002 & 0,998 & 4,00100 & 1,00025 & 10,00250 \\
\hline 12 & 11 & 2013 & 0,999 & 1,001 & 1,005 & 1,005 & 4,01000 & 1,00250 & 11,02750 \\
\hline 13 & 12 & 2014 & 1,002 & 1,003 & 1,003 & 1,001 & 4,00900 & 1,00225 & 12,02700 \\
\hline 14 & 13 & 2015 & 1,006 & 1,004 & 1,006 & 1,003 & 4,01900 & 1,00475 & 13,06175 \\
\hline 15 & 14 & 2016 & 1,001 & 1,004 & 1,004 & 0,999 & 4,00800 & 1,00200 & 14,02800 \\
\hline 16 & 15 & 2017 & 1,014 & 1,016 & 1,004 & 1,003 & 4,03700 & 1,00925 & 15,13875 \\
\hline 17 & 16 & 2018 & 1,013 & 1,008 & 1,008 & 1,007 & 4,03600 & 1,00900 & 16,14400 \\
\hline 18 & 17 & 2019 & 1,017 & 1,007 & 1,009 & 1,004 & 4,03700 & 1,00925 & 17,15725 \\
\hline 19 & \multicolumn{2}{|c|}{ Sum } & 17,163 & 17,127 & 17,117 & 17,074 & 68,481 & 17,120 & 153,8898 \\
\hline 20 & \multicolumn{2}{|c|}{$y_{j}$} & 1,010 & 1,007 & 1,007 & 1,004 & 4,028 & 1,007 & \\
\hline 21 & \multicolumn{2}{|c|}{$b_{j}$} & 0,00178 & 0,00028 & 0,00014 & 0,00192 & & & \\
\hline
\end{tabular}

The average values of quarterly indices for each year are used for the description of the trend section. The average values of quarterly indices for each quarter are used for the description of seasonal section. Therefore, it is necessary to add data concerning average values to Tab. 1 . These values are calculated in Tab. 3 .

\subsection{The Determination of the Seasonal Component within the Time Series}

Fig. 4 represents the monitored indices of time series, which show unsystematic fluctuations within the particular year. This means, that in the first quarter the value of the 
index is the highest. In the second and third quarter we can see a decline to approximately same values. Finally, the lowest value is in the fourth quarter. Therefore, the analyzed series can be considered as a time series with a seasonal component. The overall trend of time series is increasing.

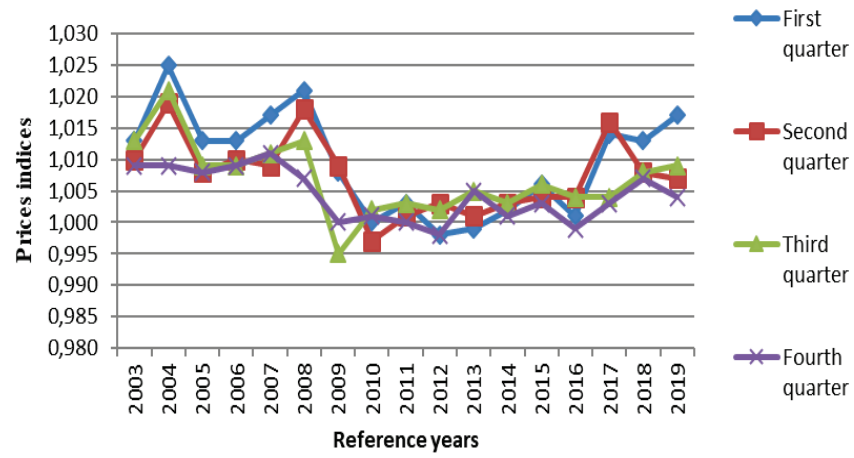

Figure 4 The average quarterly indices of prices for a particular year.

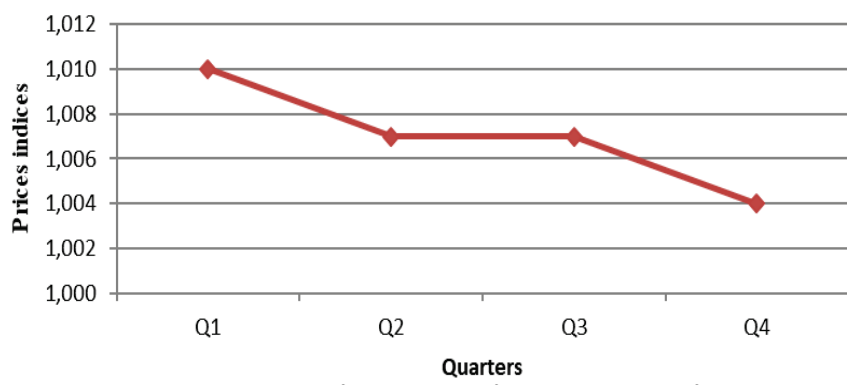

Figure 5 The average values of year indices of the development of prices within the construction industry for particular years for the section no. 803 - Residential buildings (KS no. 111).

Fig. 5 also shows the seasonality for the particular years. It is necessary to know the average values of quarterly indices in order to describe the seasonal component for particular years. They can be found in Tab. 3. The average value is determined out of these four values (line no. 20, column no.
7). The seasonal deviations of the averages for particular quarters also have to be determined and compared to the overall average.

\subsection{The Determination of the Trend Component of the Time Series}

Fig. 6 can be created based on the average values of quarterly indices for particular years.

Based on the graph mentioned above, we can create the trend line along with a relevant trend equation using MS Excel program.

The created equation looks like this:

$$
y(x)=0.0002 x^{2}-0.0033 x+1.0201
$$

In the next step, it is necessary to adjust the equation of the trend by using the deviations of particular quarters from Tab. 3 (line no. 21).

Following equations result from the mentioned sequence:

$y(x)=0.0002 x^{2}-0.0033 x+1.0201+0.00178$

pre $1^{\text {st }}$ quarter

$y(x)=0.0002 x^{2}-0.0033 x+1.0201+0.00028$

pre $2^{\text {nd }}$ quarter

$y(x)=0.0002 x^{2}-0.0033 x+1.0201+0.00014$

pre $3^{\text {rd }}$ quarter

$y(x)=0.0002 x^{2}-0.0033 x+1.0201+0.00192$

pre $4^{\text {th }}$ quarter

where $x$ represents the year, $x=1$ for the year 2003, $x=2$ for the year 2004, $x=3$ for the year 2005, etc.

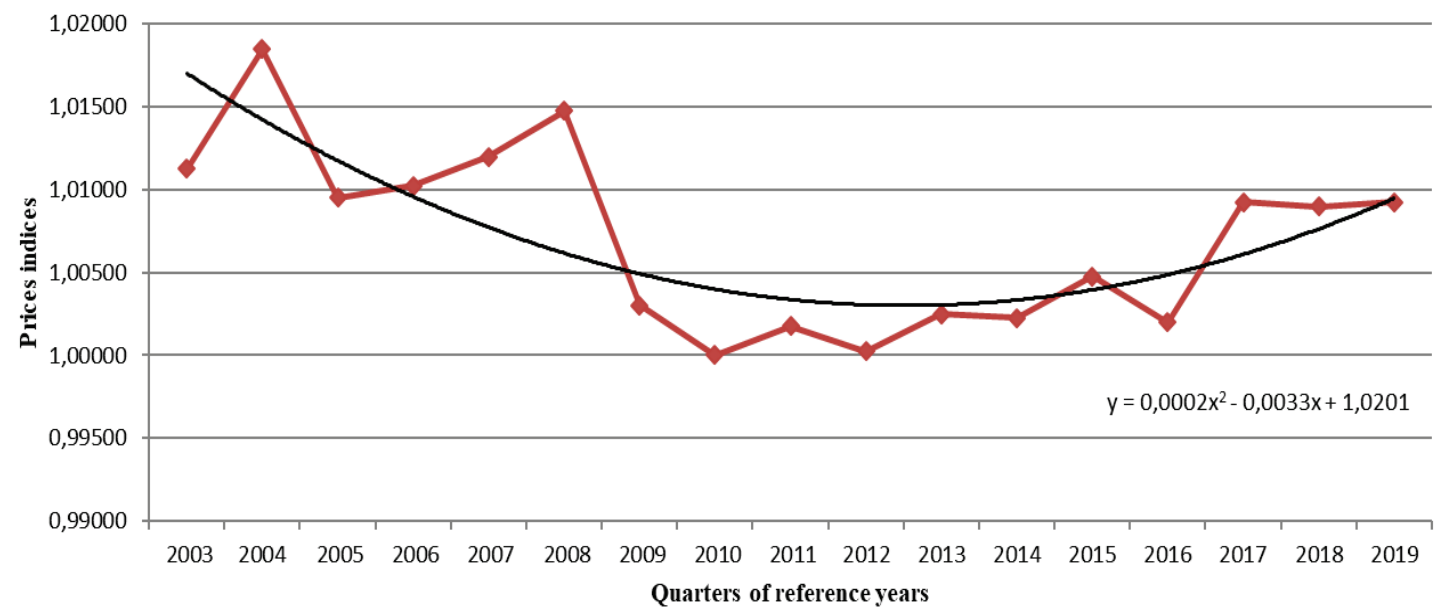

Figure 6 The average values of quarterly indices of price development within the construction industry for the section no.803 - Residential buildings (KS no. 111) during the monitored years.

Based on these relations, it is possible to determine the values of quarterly indices for the next period of quarters (Tab. 4).
If the realization of a construction is supposed to take for example from 2-3 years, it is recommended to do the forecast for this period. However, the accuracy of the calculation for 
a longer period would be insufficient. The principle that should be applied when predicting for a period of a long time ahead is that there must be available minimum of three times more past information (data) than is the number of forecasted data [1].

Table 4 The values of quarterly indices for the section no. 803 - Residential buildings (KS no. 111) for the next three years.

\begin{tabular}{|l|c|c|c|}
\hline & \multicolumn{3}{|c|}{ Year } \\
\hline QUARTER & 2020 & 2021 & 2022 \\
\hline $1^{\text {st }}$ quarter & 1,0273 & 1,0314 & 1,0359 \\
\hline $2^{\text {nd }}$ quarter & 1,0258 & 1,0299 & 1,0344 \\
\hline $3^{\text {rd }}$ quarter & 1,0256 & 1,0297 & 1,0342 \\
\hline $4^{\text {th }}$ quarter & 1,0274 & 1,0315 & 1,0360 \\
\hline
\end{tabular}

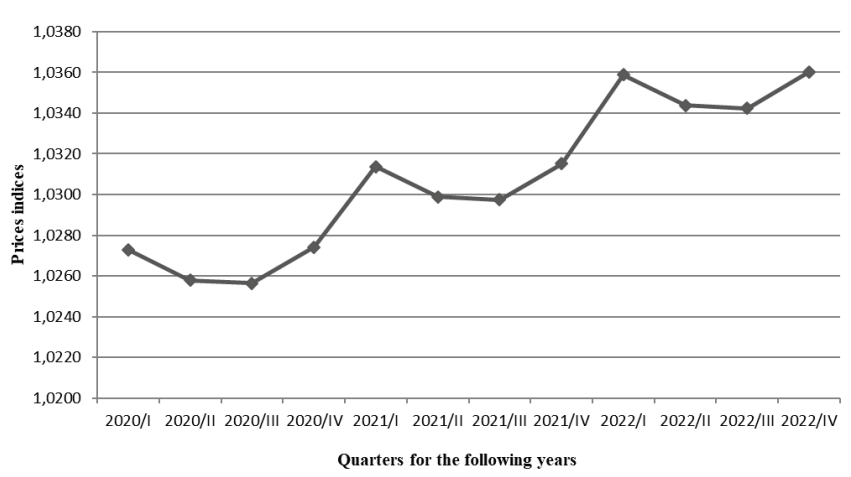

Figure 7 Graph of quarterly indices of price development in construction industry for the section no. 803 - Residential buildings (KS no. 111) for the next three years (year 2020, 2021, 2022).

The contractor can apply some of the other forecasting methods to determine the price development, as well as the increase of costs of the production. The contractor can also estimate this development for the required period (most often for the time of the realization of the construction) based on his experience and professional knowledge. Nevertheless, every contractor should definitely take into account the risk of the price development, especially in the times of price fluctuations, and include it in the tender price. Tab. 5 presents the comparison between the forecast and the reality, which is known so far for the year 2019. The following table shows the quarterly indices of the price development based on the Statistical Office of the Slovak Republic (www.statistic.sk) [20] for the section no. 803 and for the classification of structures no. 111.

Table 5 The values for quarterly indices for the section no. 803 - Residential buildings ( $K S$ no. 111) - the reality and predicted value.

\begin{tabular}{|c|c|c|}
\hline \multicolumn{2}{|c|}{ Quildings (KS no. 111) - the reality and predicted value. } \\
\hline $\begin{array}{c}2019-\text { Section no. 803 } \\
\text { Residential buildings } \\
\text { (KS no. 111) }\end{array}$ & $\begin{array}{c}2019-\text { Trend without } \\
\text { the seasonal component }\end{array}$ \\
\hline $1^{\text {st }}$ quarter & 1,017 & 1,010 \\
\hline $2^{\text {nd }}$ quarter & 1,007 & 1,009 \\
\hline $3^{\text {rd }}$ quarter & 1,009 & 1,008 \\
\hline $4^{\text {th }}$ quarter & 1,004 & 1,010 \\
\hline
\end{tabular}

\section{DISCUSSION}

The results of our study point to a growth in the construction price index. In 2005, Goh in his studies [7] pointed out to the need to apply sophisticated techniques when determining prices in construction and housing policy tenders, among other in regard to the rising expansion of construction in the society. Authors in the reference [15] add that this is a very complicated process in which the lowest price may not automatically provide the tender to the contractor. No less important factors affecting the final costs are the following: the company's experience in similar tenders, the number of successful construction projects, and the number of projects that required an additional increase in funding.

The contractor can individually decide to implement the influence of time factor or not, based on the anticipated trend of price development for the construction and assembly work, the expected duration of construction and the fact that the offering price is subject to the time development of price. It is recommended to implement the time factor influence especially in cases when developer insists on the price without the possibility of changing it (Fixed price).

\section{CONCLUSION}

The findings of this paper may also be applicable in other Visegrad group countries (V4 - Hungary, Poland, Czech Republic, Slovak Republic), but also in countries with economic characteristics similar to the Slovak Republic. The authors are aware of the application of simpler statistical methods on the data sample of the Slovak Republic. However, they consider that their practical applicability is of importance in bidding since it takes into account the estimated contractual price developments in construction.

\section{Acknowledgment}

This paper is supported and funded from KEGA grant no. 019STU-4/2018, entitled "The process of integrating mentoring and coaching into teaching at technical universities".

\section{Notice}

The paper was presented at PBE2020 - International Scientific Conference "People, Buildings and Environment 2020". The $14^{\text {th }}$ conference was held in the Rožnov pod Radhoštěm city, the Czech Republic, from 7 to 9 October 2020. The paper will not be published anywhere else.

\section{REFERENCES}

[1] Abraham, B. \& Ledolter, J. (1983). Statistical Methods for Forecasting. A John Wiley \& Sons, Inc., New York. https://doi.org/10.1002/9780470316610

[2] Amuda Yusuf, G. \& Mohamed, S. F. (2014). Perceived benefits of adopting standard - based pricing mechanism for mechanical and electrical services installations. Australasian Journal of Construction Economics and Building, 14(2), 104-119. https://doi.org/10.5130/AJCEB.v14i2.3864

[3] Bajaj, S., Garg, R., \& Sethi, M. (2018). Total quantity management: a critical literature review using Pareto analysis. International Journal of Productivity and Performance Management, 67(1), 128-154. 
https://doi.org/10.1108//JPPM-07-2016-0146

[4] Boddy, R. \& Smith, G. (2009). Statistical Methods in Practice: for Scientists and Technologists. John Wiley \& Sons, Ltd. https://doi.org/10.1002/9780470749296

[5] Dziadosz, A., Tomczyk, A., \& Kaplinski, O. (2015). Financial risk estimation in construction contracts. Procedia Engineering, 122, 120-128. https://doi.org/10.1016/j.proeng.2015.10.015

[6] Ernest, K., Theophilus, A., Amoah, P., \& Emmanuel, B. B. (2019). Identifying key economic indicators influencing tender price index prediction in the building industry: A case study of Ghana. International Journal of Construction Management, 19(2), 106-112. https://doi.org/10.1080/15623599.2017.1389641

[7] Goh, B. H. (2005). The dynamic effects of the Asian financial crisis on construction demand and tender price levels in Singapore. Building and Environment, 40(2), 267-276. https://doi.org/10.1016/j.buildenv.2004.07.012

[8] Hyari, K. H., Tarawneh, Z. S., \& Katkhuda, H. N. (2016). Detection Model for Unbalanced Pricing in Construction Projects: A Risk-Based Approach. Journal of Construction Engineering and Management, 142(12). https://doi.org/10.1061/(ASCE)C0.1943-7862.0001203

[9] Chen, M. \& Li, Q. M. (2009). Study on the Application of Price Adjustment Formulae in House Building. International symposium on advancement of construction management and real estate, Vol. 1-6, 2117-2121. ISBN: 978-962-367-675-5.

[10] Jarrett, J. (1987). Business Forecasting Methods, Basil Blackwell Publishers. Oxford and Cambridge. ISBN: 9780631152897.

[11] Kissi, E., Adjei-Kumi, T., Badu, E., \& Boateng, E. B. (2017). Factors affecting tender price in the Ghanaian construction industry. Journal of Financial Management of Property and Construction, 22(3), 252-268. https://doi.org/10.1108/JFMPC-09-2016-0044

[12] Kendall, M. G. \& Hill, A. B. (1953). The Analysis of Economic Time-Series-Part I: Prices. Journal of the Royal Statistical Society. Series A (General), 116(1), 11-34. https://doi.org/10.2307/2980947

[13] Kuda, F., Wernerova, E., \& Endel, S. (2015). Selection of a Construction Contractor for Public Contracts in the Czech Republic according to Safe Tender Price. In: Proceedings of the 2015 international conference on architectural, civil and hydraulics engineering. AER - Advances in Engineering Research. Vol. 44, 65-68.

[14] Lacko, G. (2011). Modeling the residual market value of construction equipment under changed economic conditions. Journal of Construction Engineering and Management, 137(10), 806-816. https://doi.org/10.1061/(ASCE)C0.1943-7862.0000279

[15] Lue, S. S., Son, P. V. H., \& Nhung, P. T. H. (2015). Optimize negotiation price in construction procurement using Bayesian Fuzzy Game Model. KSCE Journal of Civil Engineering, 19(6), 1566-1572. https://doi.org/10.1007/s12205-014-0522-2

[16] Othman, A. A., Abd Rahman, S., Sundram, V. P. K., \& Bhatti, M. A. (2015). Modelling marketing resources, procurement process coordination and firm performance in the Malaysian building construction industry. Engineering Construction and Architectural Management, 22(6), 644-668. https://doi.org/10.1108/ECAM-02-2014-0030

[17] Safaei, A., Freire, F., \& Henggeler Antunes, C. (2015). A life cycle multi-objective economic and environmental assessment of distributed generation in buildings. Energy Conversion and Management, 97, 420-427.

https://doi.org/10.1016/j.enconman.2015.03.048
[18] Samani, P., Gregory, J., Leal, V., Mendes, A., \& Correia, N. (2018). Lifecycle cost analysis of prefabricated composite and masonry buildings: Comparative study. Journal of Architectural Engineering, 24(1). https://doi.org/10.1061/(ASCE)AE.1943-5568.0000288

[19] Sinyaev, V. (2016). Analytical assessment of outsourcing services' marketing in construction industry. Ekonomika. Biznes. Banki. Vol. 8, 177-186. ISSN: 2304-9596. (in Russian)

[20] Statistical office of the Slovak republic. Available on: www.statistics.sk

[21] Surhone, L. M., Timpledon, M. T., \& Marseken, S. F. (2010). Pareto Analysis. VDM Publishing, p. 76. ISBN: 978613046141.

[22] Vrbka M. (2020). Parametrické rozpočtováni - inovace zpusobu určování nabidkových cen ve stavebním podniku (Parametric budget estimation - Innovation of the method of determining bid prices in a construction company). Dizertačná práca, Ústav stavební ekonomiky a rízení, VUT Brno, 2020, p. 106. (in Czech)

[23] Wang, Z. Y. \& Rangaiah, G. P. (2017). Application and Analysis of Methods for Selecting an Optimal Solution from the Pareto-Optimal Front obtained by Multiobjective Optimization. Industrial \& Engineering Chemistry Research, 56(2), 560-574. https://doi.org/10.1021/acs.iecr.6b03453

[24] Chajdiak J. et al. (1997). Statistické metódy v praxi, 2. vydanie, ISBN 8-85659-08-5 (in Czech)

\section{Authors' contacts:}

Ing. Helena Ellingerová, PhD, Assist. Prof.

Department of Building Technology,

Faculty of Civil Engineering,

Slovak University of Technology in Bratislava,

Radlinského 11, 81368 Bratislava, Slovak Republic

Ing. Zora Petráková, PhD, Assist. Prof.

The Institute for Forensic Engineering,

Faculty of Civil Engineering,

Slovak University of Technology in Bratislava,

Radlinského 11, 81368 Bratislava, Slovak Republic

Ing. Ingrida Skalíková, $\mathrm{PhD}$

(Corresponding author)

The Institute for Forensic Engineering,

Faculty of Civil Engineering,

Slovak University of Technology in Bratislava,

Radlinského 11, 81368 Bratislava, Slovak Republic

ingrida.skalikova@stuba.sk 